\title{
EL TERREMOTO CHILENO DEL 27 DE FEBRERO DE 2010: ANÁLISIS PRELIMINAR DE LAS CONSECUENCIAS EN LA CIUDAD DE VALDIVIA
}

\author{
Carlos Rojas Hoppe ${ }^{1}$ y Silvia Díez Lorente ${ }^{2}$ \\ Instituto de Ciencias Ambientales y Evolutivas. Universidad Austral de Chile ${ }^{1}$ \\ Instituto de Manejo de Bosques, Producción y Medio Ambiente. Universidad Austral de Chile ${ }^{2}$
}

\section{RESUMEN}

El mayor sismo que haya afectado a la ciudad de Valdivia con posterioridad al famoso terremoto de 1960 fue el generado por el evento (Mw 8,8) del 27 de febrero de 2010 en la zona central de Chile. La intensidad asignada para la ciudad de Valdivia alcanzó el valor VI en la escala de Mercalli. Con el objeto de comprender la distribución espacial de los daños a la infraestructura urbana, se relacionó ésta con las condiciones locales de suelo. Los antecedentes de la historia sísmica y del desarrollo urbano de Valdivia proporcionan información valiosa que se agregó al análisis. La diferente severidad con la que el sismo repercutió en los diversos barrios de Valdivia, guarda una estrecha relación con las unidades geomorfológicas y los tipos de suelos de fundación existentes en la ciudad. Se pudo establecer una buena coincidencia con la respuesta sísmica de los suelos prevista para la ciudad en estudios previos.

Palabras clave: terremoto, Valdivia, suelos, respuesta sísmica.

\section{ABSTRACT}

The chilean earthquake of february 27, 2010:

Preliminary analysis of its consequencesin the city of Valdivia

The main seism affecting the city of Valdivia after the famous earthquake of 1960 was the event $(\mathrm{Mw}=8.8)$ which occurred on February 27, 2010 in central Chile. It has been assigned an intensity of Mercalli VI for the city of Valdivia. In order to understand the spatial distribution of the damage caused to urban infrastructure, the latter was related to the local soil conditions. Backgrounds of both the seismic history and the city development provide valuable information which was added to the analysis.

The dissimilar severity the seism had on the different quarters of Valdivia is closely associated with the geomorphological units and the foundation soil types which are present in the city.

A good coincidence with the seismic response of the soils foreseen for the city in previous studies could be established.

Key words: earthquake, Valdivia, soils, seismic response.

\section{INTRODUCCIÓN}

Escenario principal del sismo de mayor magnitud en el planeta, casi exactamente medio siglo después la ciudad de Valdivia (39 $48^{\prime} 30^{\prime \prime}$ S, $73^{\circ} 14^{\prime} 30^{\prime \prime}$ W, Figura 1) fue alcanzada por las ondas del gran terremoto del 27 de febrero de 2010. En vísperas de la culminación de las actividades estivales que se organizan anualmente en torno a la fecha del aniversario de su fundación, el paso de la perturbación sísmica por la ciudad causó enorme inquietud y alarma.

\footnotetext{
crojas@uach.cl - Teléfono: +56 632293192.

silvia.diez@uach.cl - Teléfono: +56 632221638.
} 
Aún cuando los daños fueron considerablemente menores en comparación con los ocurridos en las regiones de la zona central de Chile, los efectos en la ciudad fueron significativos. En Valdivia la duración perceptible alcanzó aproximadamente a 2 minutos, durante los cuales miles de sobrevivientes del gran terremoto del 22 de mayo de 1960 no pudieron evitar recordar tan infausto acontecimiento. Protagonistas de los largos y sacrificados años de reconstrucción requeridos para levantar a la ciudad más devastada por aquel evento, hito en la historia de la ciudad e ícono en la sismología mundial, ellos comprendieron como pocos la magnitud de la tragedia que comenzaba a develarse en el territorio afectado.

Con el objetivo de comprender la distribución espacial del daño a la infraestructura urbana, se relacionó ésta con las condiciones locales de suelo. Los antecedentes de la historia sísmica y del desarrollo urbano de Valdivia proporcionan información valiosa, que se agregó al análisis.

Figura 1. Ubicación de la ciudad de Valdivia.
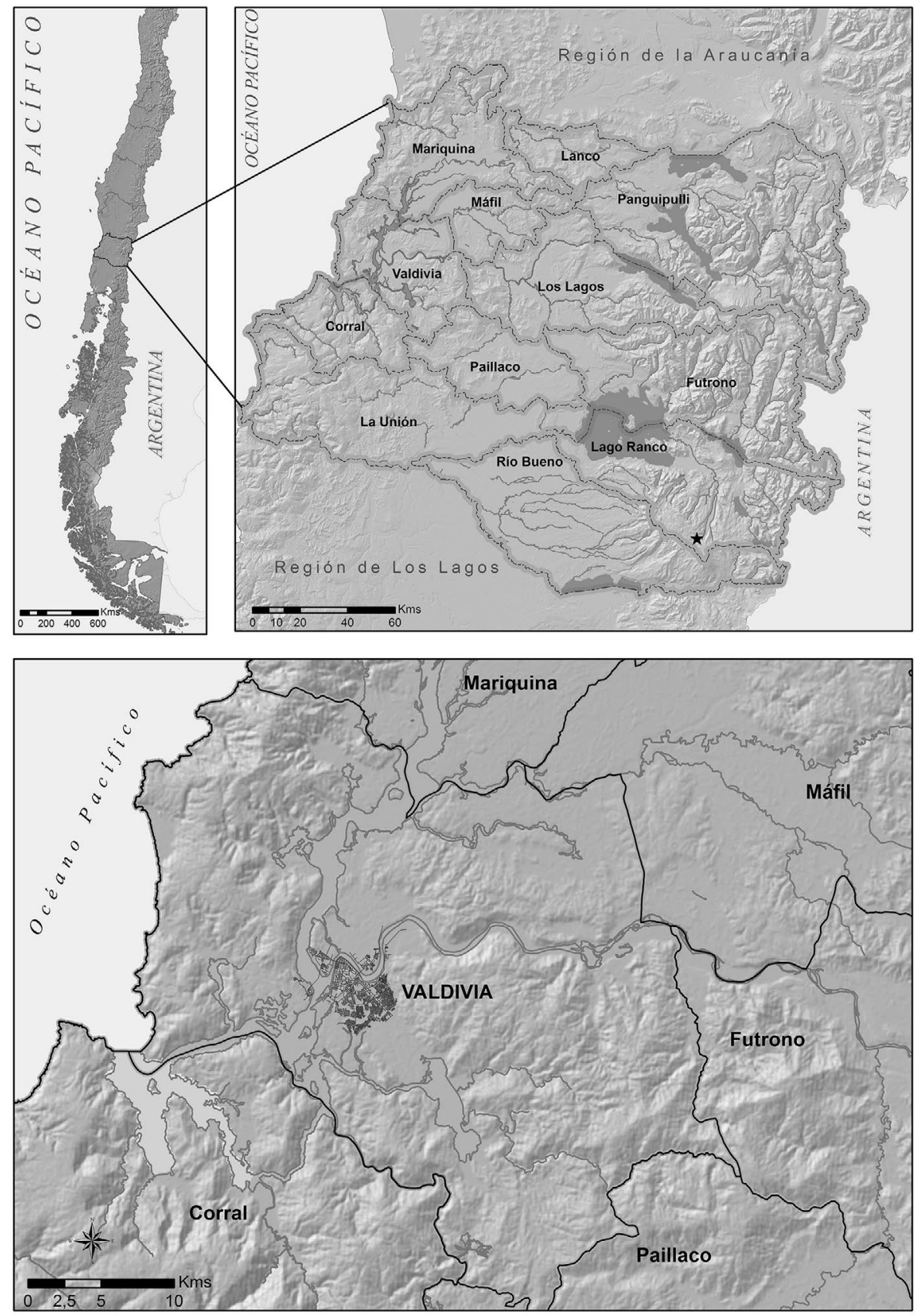

Elaboración propia. 


\subsection{Historia sísmica de la ciudad de Valdivia}

Al igual que muchas otras ciudades chilenas y latinoamericanas, Valdivia ha sido afectada por varios sismos de diversas magnitudes y diferentes efectos a lo largo de su historia de más de 460 años. Los que provocaron mayor destrucción fueron los de 1575, 1737, 1837, 1907 y 1960 (Rojas, 2010; Urrutia y Lanza, 1993). No obstante, los catálogos de sismos nacionales y publicaciones relacionadas con la historia de la ciudad de Valdivia reportan la ocurrencia de numerosos eventos adicionales que, habiendo afectado mayormente a otras zonas del país, también fueron sentidos en el sur de Chile y particularmente en la ciudad de Valdivia (Almonacid, 1998; Goll, 1904; Greve, 1964; Lomnitz, 1970, 2004; Taulis, 1938). Una recopilación detallada de ellos fue realizada recientemente por Rojas (2010), quien advierte que el incremento en el número de sismos reportados a partir de la segunda mitad del siglo XIX se explica por el minucioso registro que de los fenómenos atmosféricos y telúricos diarios comenzaron a hacer los colonos alemanes, en particular Karl Anwandter. Probablemente de haberse llevado un registro similarmente riguroso en los siglos previos el catálogo de sismos se hubiera enriquecido notablemente. De destacar es el hecho que de los numerosos terremotos que han afectado a la ciudad en sus más de cuatro siglos y medio de existencia hay dos que según los antecedentes disponibles tuvieron efectos muy similares (Rojas, 2000; Saint Amand, 1961), según puede observarse en el Cuadro 1.

Cuadro 1. Grandes terremotos en la ciudad de Valdivia.

\begin{tabular}{|l|c|c|c|c|}
\hline \multicolumn{1}{|c|}{ FECHA } & TSUNAMI & $\begin{array}{c}\text { INTENSIDAD } \\
(\mathrm{MM})\end{array}$ & $\begin{array}{c}\text { MAGNITUD } \\
\text { RICHTER }\end{array}$ & $\begin{array}{c}\text { MAGNITUD DE } \\
\text { MOMENTO }\end{array}$ \\
\hline 1575 (DIC.16) & + & X-XI & $8,5 *$ & \\
\hline 1737 (DIC.24) & - & IX-X & $7,5-8,0 *$ & \\
\hline 1837 (NOV.07) & + & $\mathrm{X}$ & $8,0 *$ & \\
\hline 1907 (JUN. 13) & - & VII-VIII & $6,8 *$ & 9,5 \\
\hline 1960 (MAY.22) & + & $\mathrm{X}$ & 8,5 & \\
\hline * Magnitud estimada + Presente - Ausente
\end{tabular}

Fuente: Modificado de Rojas (2010).

\subsection{El sismo del 22 de mayo de 1960 en Valdivia}

Sin duda alguna, el terremoto del 22 de mayo de 1960 ocurrido en el sur de Chile se asocia indefectiblemente a la ciudad de Valdivia. Este sismo, el de mayor magnitud habido en el planeta desde que se tienen registros instrumentales (Magnitud del Momento Sísmico Mw 9,5), liberó el 35\% de la energía de todos los terremotos del siglo XX. La Magnitud del Momento Sísmico (Hanks \& Kanamori, 1979) está basada en el cálculo del momento sísmico (Mo) que es una medida del tamaño de un sismo en función del área de la ruptura de la falla, el promedio del desplazamiento de la misma y la fuerza necesaria para generar este movimiento. De esta forma representa, de manera más directa y precisa que otro tipo de magnitudes, la energía liberada en la fuente sísmica y es comúnmente utilizada para sismos grandes, puesto que no tiene los inconvenientes, para este tipo de sismos, que otras escalas de magnitud.

En sentido estricto, se trató de un complejo de procesos naturales encadenados e interrelacionados, incluyendo no sólo diversos sismos, sino también un tsunami, movimientos de remoción en masa, la obturación del desagüe final de un sistema de lagos andinos interconectados y una erupción volcánica en la cordillera de los Andes. Una de las consecuencias geomorfológicas más destacadas del sismo fue la subsidencia cosísmica del terreno en aproximadamente 1,8 m, que determinados lugares se incrementó en al menos un metro debido a la compactación de materiales no consolidados, sobre todo sedimentos arenosos y arcillosos y rellenos artificiales (Rojas, 2000; 2010).

El sismo tuvo especial relevancia por la diversidad de fenómenos acompañantes, la distribución espacial de los efectos y la cuantía de los daños. La zona afectada abarcó una superficie de $150.000 \mathrm{~km}^{2}$, comprendida entre Concepción y el extremo meridional de la isla de Chiloé, alcanzando una intensidad máxima de X en Valdivia y Puerto Montt. La sacudida tuvo una duración de tres minutos y medio (Rojas, 2010). 
Considerando los efectos directos de aquel terremoto, del tsunami que lo siguió minutos después y de la inundación extrema causada 2 meses más tarde por la descarga de las aguas represadas en el lago Riñihue, la mayor diversidad y cuantía de los daños se produjo en la ciudad de Valdivia y su entorno. Este complejo evento sísmico es un ícono para la sismología mundial, pero sobre todo constituye un hito en la historia de Valdivia.

La destrucción de la ciudad fue estimada en un $80 \%$, con grandes daños en viviendas, edificios, calles e infraestructura urbana ( $90 \%$ de las industrias y $80 \%$ de los locales comerciales afectados en mayor o menor grado, $55 \%$ de las viviendas averiadas), apreciándose una interesante distribución espacial de los efectos en relación a los suelos de fundación (Rojas, 2010).

\section{EL SISMO DEL 27 DE FEBRERO DE 2010 EN VALDIVIA}

El último gran terremoto ocurrido en Chile (27 de febrero de 2010, 3:34 AM; Mw=8,8) cuyas características sismológicas y sismotectónicas fueron descritas por Barrientos (2010) se hizo sentir en la ciudad con una intensidad VI en la escala modificada de Mercalli (Rojas, 2010). En la Región de Los Ríos no se produjeron víctimas fatales ni heridos de consideración, y la capital regional fue la ciudad más afectada. Después del desconcierto inicial en esa madrugada, a medida que transcurrían las horas y de alguna forma se hacía posible la comunicación entre los diferentes sectores urbanos, fue haciéndose patente que los efectos en los diversos sectores de la ciudad fueron muy disímiles. El corte del suministro eléctrico en gran parte de la ciudad contribuyó considerablemente a generar desorientación y preocupación; en numerosos barrios la falta de energía eléctrica se mantuvo durante más de 24 horas. La mañana del 27 de febrero muchas personas se volcaron a las calles a conocer los efectos del sismo. Para gran parte de ellas constituyó una sorpresa el descubrir que los mayores daños estaban circunscritos a sectores bien definidos.

\subsection{Caracterización geomorfológica de Valdivia}

Para comprender la localización y las características de los daños habidos en Valdivia con ocasión del sismo del 27 de febrero de 2010 hay que analizar la constitución geológica y geomorfológica de esta parte de la ciudad, así como los antecedentes existentes sobre los efectos de sismos previos. Parte importante del sitio de la ciudad de Valdivia se desarrolla sobre una terraza de origen fluvial a una altura promedio de 9 metros sobre el nivel del río. La terraza otorga una fisonomía característica al paisaje valdiviano, levantándose abruptamente desde los ríos o desde las llanuras de inundación en la mayor parte de los casos, configurando un paisaje de superficies más bien planas con alturas extremas variables entre 6 y algo más de 20 metros sobre los ríos. En el sector céntrico de la ciudad (núcleo tradicional urbano) la terraza fue rebajada en alrededor de 1 metro hacia principios del siglo XX, atenuándose las pendientes hacia el río (Guarda, 2001). Todas ellas están constituidas por una arenisca con abundantes componentes de origen volcánico, conocida localmente como cancagua (Rojas, 2003). Las terrazas se presentan delimitadas por escarpes con otras unidades geomorfológicas situadas a menor altura. Aparece más desmembrada en la parte occidental de la ciudad, ofreciendo un aspecto más continuo en la oriental. Sobre esta terraza se encuentra emplazada la mayor parte de la ciudad de Valdivia (Rojas, 2000; 2003). En la parte sur de la ciudad se presenta profundamente disectada por algunos cursos de agua que generan pequeños valles locales.

Así, la configuración del relieve de la parte occidental, sur y suroccidental de la ciudad se presenta con aspecto de mesetas separadas unas de otras sin ordenamiento regular por sectores bajos sinuosos, constituidos por paleocauces tallados en las terrazas y ocupados por humedales interiores (Rojas, 2003), algunos parcialmente rellenados por acción antropogénica. También presenta importante expresión la planicie aluvial del río Calle Calle - Valdivia, con amplios sectores ribereños originalmente ocupados por vegas y pantanos que, al igual que los paleocauces, desde la fundación de la ciudad han sido objeto de un relleno artificial, pero especialmente desde mediados del siglo XIX (Rojas, 2000, 2003). Un caso emblemático es el del antiguo humedal interior localizado en el núcleo tradicional urbano de Valdivia, que fue objeto de relleno artificial desde hace varios siglos (Watanabe y Karzulovic, 1960; Weischet, 1960; Rojas, 2000), cubriéndose la depresión natural o hualve con una mezcla heterogénea de limo, arena 
y ripio con escombros, maderas, basura orgánica y desechos, con un espesor en general menor a 3 metros y excepcionalmente hasta 9 metros (Barozzi y Lemke, 1966). Pese a los movimientos de tierra, los rellenos y las edificaciones realizadas en las últimas décadas, la depresión natural de ese paleocauce es perfectamente apreciable a lo largo de varias manzanas en el centro de la ciudad, algunas de las cuales permanecen con importantes superficies sin construcciones. Estos terrenos bajos también han sido parcialmente urbanizados (Rojas, 2010); la mayoría acusa afloramiento de aguas subterráneas y anegamientos pluviales en invierno. Donde no ha habido intervención antrópica, la terraza fluvial baja con pendientes casi verticales al nivel topográfico ocupado por las vegas y los paleocauces, que en el caso de aquellos de tipo ripariano quedan dentro del alcance de las crecidas del río (Rojas, 2002).

Con ocasión del terremoto de 1960, el área en cuestión fue precisamente aquella que concentró la más severa y más numerosa destrucción en el centro de la ciudad, excepción hecha de los sectores a orillas del río (Rojas, 2010; Weischet, 1960). Estudios realizados con posterioridad a ese sismo (Barozzi y Lemke, 1966) revelaron la ubicación, características y magnitud de los rellenos artificiales en el área urbana de Valdivia. La comparación de la carta geomorfológica (Rojas, 2003; 2005b) con un plano de la ciudad de Valdivia de 1794 es muy clarificadora para apreciar la importancia de los humedales originales en el sitio de emplazamiento de Valdivia y el origen de la terraza de relleno antrópico, apreciándose especialmente el mencionado paleocauce con un trazado sinuoso de orientación general SE-NW y con un desarrollo de más de un kilómetro (Figura 2).

Figura 2. Plano iconográfico de la ciudad de Valdivia (1794).

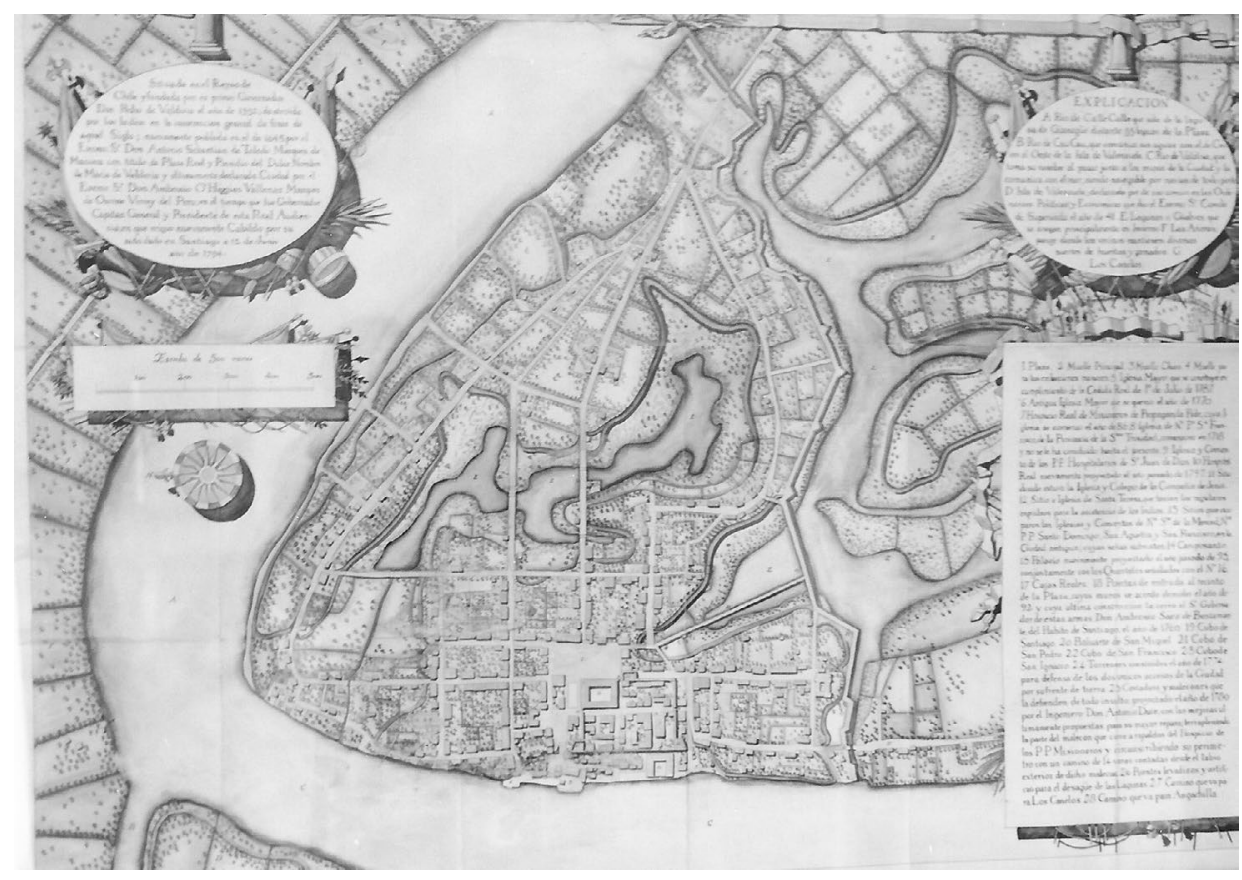

Fuente: Museo histórico y antropológico Maurice Van de Maele. Universidad Austral de Chile.

Los efectos del sismo de 1960 fueron muy severos en las riberas del río. La antigua costanera de Valdivia, de la cual aún es posible observar parte de la estructura metálica en el tramo que va desde la calle Moctezuma a la calle José Martí, fue severamente destruida por el terremoto del 22 de mayo de 1960. La subsidencia cosísmica del orden de los 2 metros contribuyó también a hacerla desaparecer, quedando ella, en el tramo mencionado, alternadamente sumergida y a la vista durante las fluctuaciones diarias de la marea.

Las características de la destrucción causada por ese sismo en ambas riberas del río Calle-Calle se explican por el comportamiento que presentaron los sedimentos naturales y el relleno artificial que se había empleado allí como suelo de fundación para algunas construcciones, para rectificar el cauce y para establecer la antigua avenida Costanera. En aquellos lugares donde los materiales rocosos más antiguos y sólidos afloraban en las márgenes escarpadas del río no se presentaron problemas. Así, después del 
sismo, a orillas del río y durante las mareas altas, la Avenida Prat se cubría totalmente de agua como consecuencia del considerable hundimiento del terreno. La estructura de la antigua costanera estaba destruida y sumergida, y en varios tramos la calzada presentaba la losa de hormigón fracturada, desplazada e inclinada. En el sector del malecón, donde la calle era de adoquines, se produjeron grietas y resaltes en la superficie debido a la compactación diferencial y al deslizamiento del material de relleno (Rojas, 2010). Las destrucciones fueron tan considerables que sólo se podía realizar un mínimo tráfico de personas y mercancías.

La actual costanera, a lo largo de todo su desarrollo, es el resultado de obras de gran envergadura que se emprendieron como parte de la reconstrucción de la ciudad, trabajos que se terminaron en el año 1966 para el tramo aguas abajo del sector del terminal de buses. Una de las medidas más relevantes para la reconstrucción de Valdivia fue restablecer la infraestructura de defensas fluviales.

Esto implicó la construcción de tablestacados y rellenos para la recuperación de los terrenos sumergidos, cambios de trazado de la línea de ribera (en algunos casos con ganancia o pérdida de terreno), levantamiento de enrocados a modo de diques, relleno y levantamiento de calles, etc. (Rojas 2000, $2002,2003,2010$ ). Todo esto tuvo importantes repercusiones en la respuesta de estos sectores frente a las crecidas del río, ya que durante los años que demoraron los trabajos, diversos barrios estuvieron expuestos a inundaciones con una alta frecuencia (Rojas, 2002; Rojas y Mardones, 2003). Las obras de reconstrucción de la Costanera de Valdivia fueron realizadas por Obras Portuarias, el tramo correspondiente al río Valdivia, y por Defensas Fluviales el sector del río Calle-Calle (Rojas, 2010). En el primer caso (aguas abajo del puente Pedro de Valdivia) la estructura posee un armado de pilotes de fierro y concreto (Figura 3a), en tanto que en el tramo entre los dos puentes existe solamente un enrocado de esquistos micáceos que sostiene el relleno efectuado detrás de este dique artificial (Figura 3b). Este relleno se efectuó extrayendo arena del lecho del río mediante dragado y vertiéndola detrás de la línea en que se estableció el enrocado (Figura 3c), además de esquistos micáceos muy alterados y escombros de los edificios destruidos por el sismo, descargados mediante camiones en el mismo sector (Barozzi y Lemke, 1966; Rojas, 2010). Para el sector del puerto fluvial se empleó como relleno principalmente arena del lecho del río.

Figura 3. Reconstrucción de la Avenida Costanera tras el terremoto de 1960.

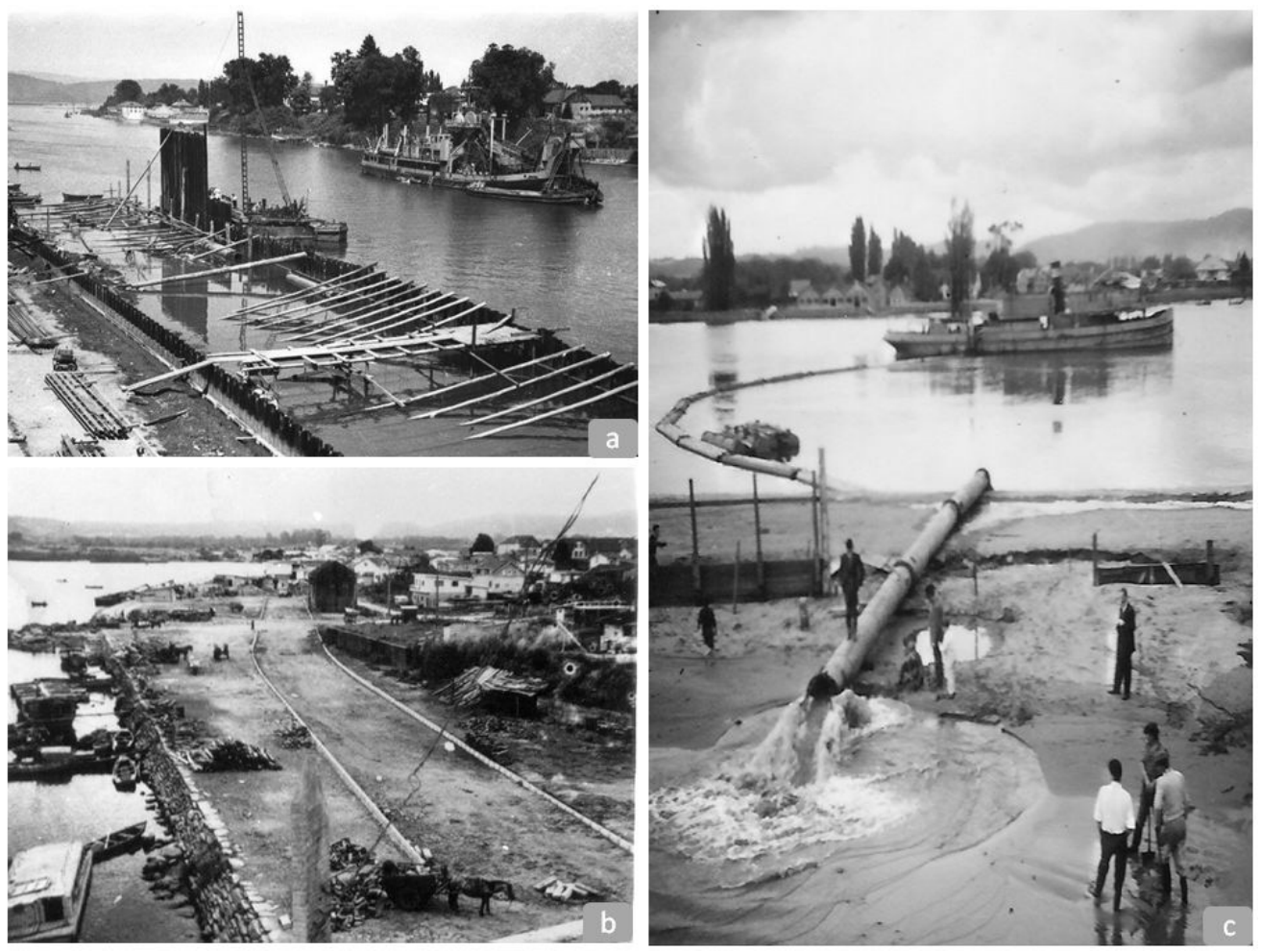

Fuente: Archivo fotográfico personal de los autores. 
En el borde de uno de los numerosos y húmedos pantanos interiores que aún caracterizaban las áreas cercanas al casco histórico de Valdivia, surgió en las últimas décadas del siglo XIX un caserío que gradualmente fue extendiéndose y constituyendo uno de los varios barrios marginales (conventillos) de la ciudad. El barrio conocido como "Beneficencia" se estableció bajo condiciones sanitarias deplorables en lo que fuera parte de un extenso humedal que se extendía al sur de la calle Beauchef, al pie de la muy disectada terraza fluvial sobre la que se desarrolla el centro comercial de la ciudad. Con el transcurso de las décadas una parte de ese humedal comenzó a ser rellenada artificialmente. En la parte más deprimida de ese pantano siempre permaneció a la vista el cauce del principal curso de agua (catrico) que drena ese humedal con un trazado este - oeste y que desagua en el río Valdivia pasando al costado del antiguo torreón español de calle General Lagos. Aún cuando a comienzos del siglo XX parte importante de ese curso de agua fue entubado y comenzó a correr subterráneamente, en el sector de Beneficencia permaneció libre, constituyéndose en un foco de insalubridad y muy susceptible a experimentar desbordes en los lluviosos inviernos del sur de Chile. De hecho, uno de los lugares donde los anegamientos en la ciudad fueron más severos y frecuentes durante todo el siglo XX fue precisamente este barrio (Rojas, 2002). Con el transcurso del tiempo los rellenos artificiales progresaron, no sólo en Beneficencia, sino que en todos los llamados barrios bajos de Valdivia, pero la localización junto al catrico le otorgó a ese sector una especial impronta de vulnerabilidad física a los anegamientos, e incluso a las inundaciones (Rojas, 2002).

El terremoto de mayo de 1960 vino a revelar que esa vulnerabilidad no estaba dada exclusivamente frente a las amenazas hidrometeorológicas, sino que además se constituyó en uno de los sectores donde los efectos del sismo adquirieron dimensiones catastróficas. Los estudios llevados a cabo por Weischet (1960) y Barozzi y Lemke (1965), Duke y Leeds (1963) y Doyel et al., (1963) concluyeron que la causa principal de los cuantiosos daños habidos en barrios como Beneficencia y otros sectores urbanos, respondían fundamentalmente a la amplificación del movimiento del suelo a causa de las malas condiciones de los suelos de fundación. Como suelos de fundación, los rellenos artificiales se encuentran no solamente en las riberas del río, en el antiguo paleocauce que recorre el centro de la ciudad y en el sector de Beneficencia, sino que tienen una importante representación en toda la ciudad de Valdivia. De acuerdo con los resultados de algunas investigaciones (Rojas, 2005a, 2010; Rubilar et al., 2007), la superficie ocupada por rellenos artificiales de diferente tipo supera largamente el $5 \%$ del área urbana. Muchos de ellos tienen un carácter furtivo, otros no parecen ser tan clandestinos e incluso abundan los que claramente son autorizados. En la mayor parte de los casos el depósito se hace sobre los bordes de los humedales, estimándose que en los últimos años la superficie de rellenos artificiales se incrementa anualmente en 5 hectáreas como mínimo.

Estos rellenos presentan una estabilidad muy baja ante eventos sísmicos, como fuera dramáticamente demostrado con los efectos el terremoto de 1960 (Weischet, 1960; Rojas, 2000, 2010) y más recientemente por los del 27 de febrero de 2010. En los más diversos sectores de la ciudad se han establecido rellenos de variada extensión y diversos espesores, especialmente en desmedro de las superficies de humedales y planicies fluviales locales. Se generan así terrazas y llanuras de relleno antropogénico (Rojas, 2003).

\subsection{Respuesta sísmica del suelo y daños provocados por el terremoto}

Al igual como había ocurrido cincuenta años atrás, los efectos fueron de severos a moderados en los sectores en que las riberas fluviales, los antiguos humedales y los paleocauces habían sido rellenados artificialmente. Escaso daño se presentó en las áreas en que la ciudad se desarrolla sobre la terraza fluvial de arenisca, cuyos suelos manifiestan una amplificación mucho menor del movimiento que aquellos constituidos por pantanos o rellenos artificiales. En estos últimos, fue posible observar casos de desplazamiento lateral y probablemente licuación de suelos. Se pudo establecer una buena coincidencia con la respuesta sísmica de los suelos prevista para la ciudad en estudios anteriores (Figura 4).

Este sismo, de tanta y tan grave repercusión en la zona centro-sur del país, provocó algunos daños desde menores a moderados en edificios del área céntrica de la ciudad, colapso de muros cortafuegos, asentamiento, desplome y deformación de casas por debilitamiento de sus bases, desprendimiento de revestimientos exteriores en edificios céntricos, agrietamiento de muros, rotura de vidrios en ventanales, rotura de aceras, soleras y calzadas, daños en matrices de agua potable, y hundimiento, agrietamiento y desplazamiento de pavimentos en el sector del puerto fluvial y a lo largo de toda la Avenida Prat. 
Figura 4. Mapa de respuesta sísmica del sector noroccidental de la ciudad de Valdivia.

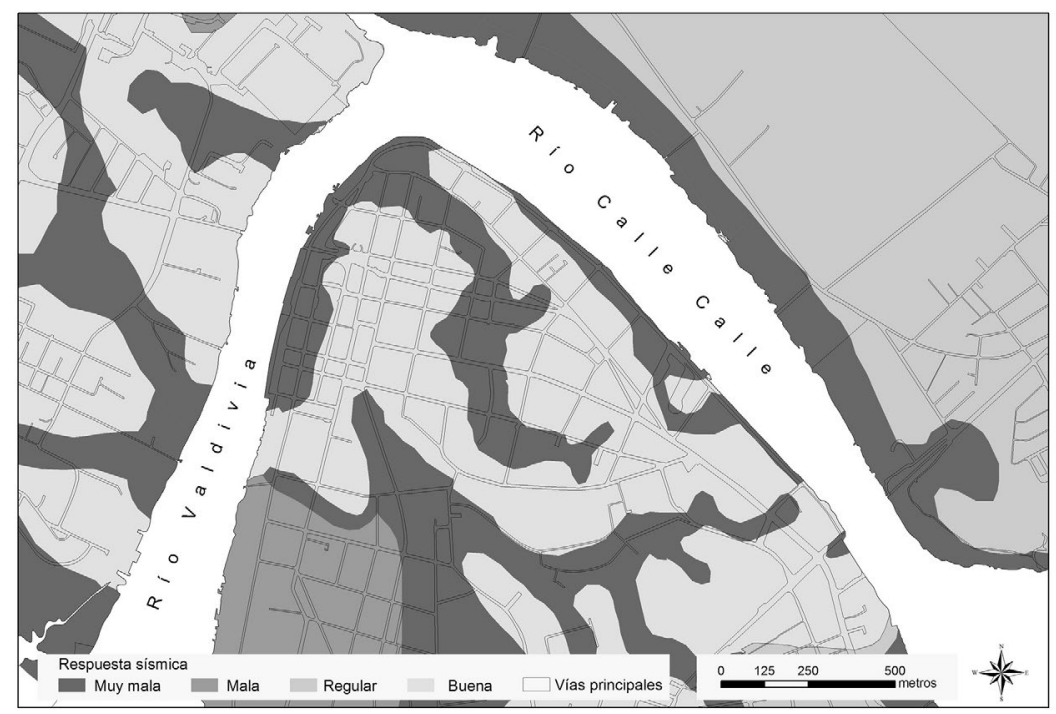

Fuente: Arenas, et al., (2004). Elaboración propia.

Según un informe inicial del Servicio de Vivienda y Urbanismo y la Seremi de Vivienda y Urbanismo, en la provincia de Valdivia 35 viviendas sufrieron daños mayores y quedaron inhabitables y 44 viviendas experimentaron daños menores, reparables (GORE, 2010). No obstante, un mes después del sismo, 91 viviendas ubicadas en diversos puntos de la ciudad habían sido catalogadas por la Dirección de Obras de la Municipalidad de Valdivia como inseguras, por poseer daños estructurales en diferentes grados (Diario Austral, 2010 b), afectando a un total de 434 personas. Las vías urbanas que registraron roturas de pavimentos se presentaron en los sectores de Yánez Zavala, Guacamayo, San Luis, Huachocopihue, Regional, Beneficencia, Corvi, Independencia, sector centro, Isla Teja, Las Animas y San Pedro, estimándose en primera instancia que las roturas urgentes de reparar alcanzaban a 1.370 metros lineales.

Los daños ocurridos en el sector céntrico de la ciudad se concentraron principalmente en el área entre las calles Arauco y Carampangue, por el sur y norte, y Walter Schmidt y Caupolicán por el Este y Oeste, respectivamente. Algunos efectos menores también se observaron en calle Camilo Henríquez entre Arauco y Cochrane, en calle Yerbas Buenas (muy cerca al sector Beneficencia) y calle Beauchef (Figura 5).

Figura 5. Mapa de respuesta sísmica del sector central de la ciudad de Valdivia.

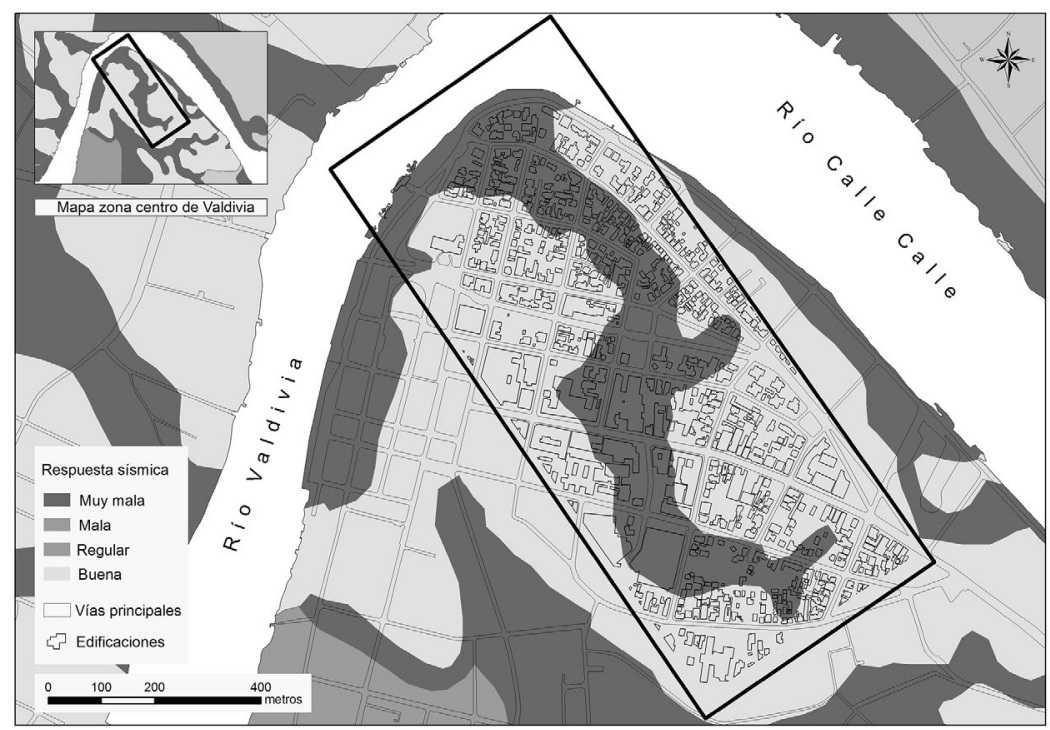

Fuente: Arenas, et al., (2004). Elaboración propia. 
Los daños principales ocurrieron en la tercera cuadra de la calle Ramón Picarte, donde se vio muy afectado el edificio donde funcionaban dependencias de la Gobernación de la provincia de Valdivia. Este quedó tan dañado que fue declarado inhabitable. También el edificio de Bienes Nacionales, ubicado a una cuadra de la Avenida Costanera, sufrió daños. Siguiendo una dirección aproximadamente norte - sur, puede trazarse una franja que abarca la zona mayormente afectada en el centro de la ciudad, la cual tiene como eje aproximado las calles Ismael Valdés y Walter Schmidt. En este sector, además del daño al edificio Ferso ya mencionado, hubo considerable destrucción en las aceras, rotura de cañerías de agua potable, caída de algunos muros cortafuegos, desprendimiento de revestimientos de muros, rotura de ventanales y otros daños. Las tiendas comerciales ubicadas en ese sector del centro experimentaron notables efectos producto de las sacudidas sísmicas. Entre las edificaciones que presentaron daños importantes destacó principalmente el edificio donde funcionaban muchas dependencias de la Gobernación Provincial de Valdivia, el cual quedó inhabitable. Así, los daños ocurridos concuerdan totalmente con las características de los suelos y de las geoformas.

Con ocasión del terremoto del 27 de febrero de 2010 en la zona centro-sur de Chile, el área que concentró los mayores daños en las riberas fluviales de la ciudad correspondió a casi toda la extensión de la Avenida Prat, entre las calles Carlos Condell y San Carlos, pero con los efectos más llamativos aguas abajo del puente Pedro de Valdivia (Figura 6). Sin duda alguna, los daños en la infraestructura urbana que más llamaron la atención fueron los que experimentó el sector ribereño al río Calle Calle/ Valdivia, particularmente en el llamado muelle Schuster, aledaño a la Gobernación Marítima. Desde el puente Pedro de Valdivia y hasta el término de la Avenida Prat, aguas abajo de la tradicional Feria fluvial, el daño fue considerable y se constituyó en el foco de la atención ciudadana que veía como el emblemático y siempre muy concurrido sector mostraba los efectos del mayor sismo que afectara a la ciudad en el medio siglo transcurrido desde aquel que la destruyera en 1960.

Figura 6. Mapa de respuesta sísmica del sector del puerto fluvial en la Avenida Costanera.

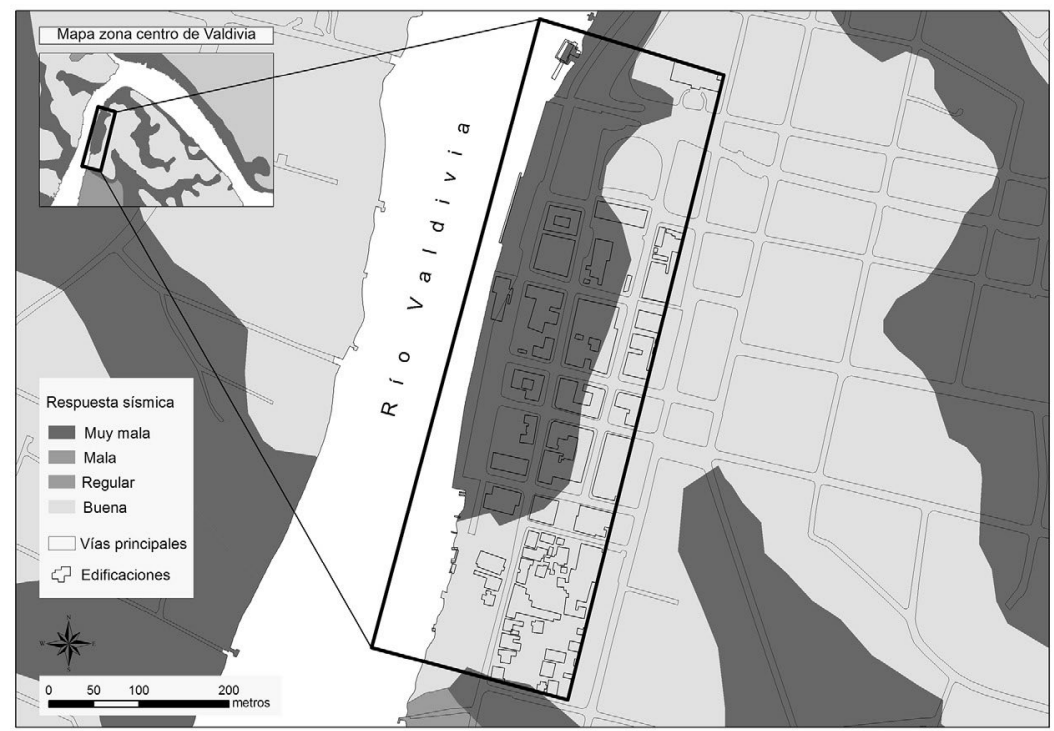

Fuente: Arenas, et al., (2004). Elaboración propia.

El sector aguas abajo del puente Pedro de Valdivia hasta el término de la Avenida Prat, que incluye la infraestructura de la tradicional feria a orillas del río y el muelle del puerto fluvial, experimentó efectos variados y localmente severos. En el sector del malecón el colapso de la loza de concreto exhibió de manera muy gráfica la movilidad de los suelos con el paso del tiempo, ya que sin duda las placas estaban "colgadas" sobre materiales que habían disminuido su volumen por compactación y erosión previas (Figura 7). El asentamiento del terreno de aproximadamente $1,20 \mathrm{~m}$ de profundidad con roturas de veredas y socavones, generó cámaras de aire de su interior que hicieron peligrar la estabilidad del terreno. Debido a ello, el muelle fue inhabilitado por la Secretaría Regional Ministerial de Obras Públicas de la Región de los Ríos. 
Figura 7. Imágenes comparativas de los daños en la Avenida Costanera (sismos de 1960 y 2010).
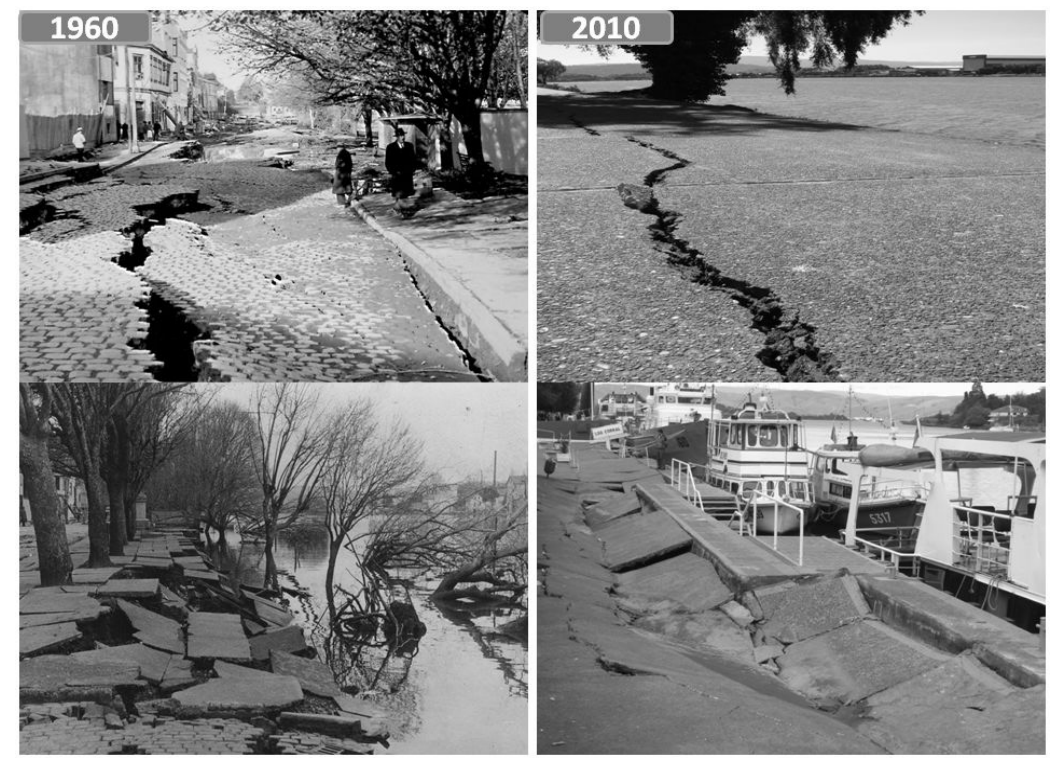

Fuente: Archivo fotográfico personal de los autores.

Ubicadas en las proximidades del río en ese sector, las dependencias del Servicio Nacional de Turismo y de la Corporación Cultural Municipal, sufrieron graves daños en su estructura. Mediante una inversión conjunta del Ministerio de Obras Públicas y el Gobierno regional de Los Ríos, posteriormente se repararon las estructuras dañadas por el terremoto. Los trabajos contemplaron la demolición de la infraestructura dañada, la pavimentación de la explanada en un tramo de 400 metros, la instalación de baldosas, la habilitación de áreas verdes y la construcción de rampas de acceso, y tuvo un costo de 950.000 US\$ (DOP, 2011).

El sector ubicado aguas arriba del puente Pedro de Valdivia experimentó fundamentalmente daños en el paseo peatonal a orillas del río. Se trató sobre todo de agrietamientos de la acera que en algunos casos superaron los $5 \mathrm{~cm}$ de ancho y varios metros de longitud, en parte también un notorio ensanchamiento y prolongación de grietas antiguas y desnivelación de los paños de pavimento en algunos tramos. Asimismo, los movimientos de las placas de cemento y la compactación del material de relleno detrás del enrocado causaron un agrietamiento del terreno junto a las aceras, que en algunos casos superaron los $30 \mathrm{~cm}$ de ancho, los $40 \mathrm{~cm}$ de profundidad y 10 metros de longitud (Figura 8).

Figura 8. Mapa de respuesta sísmica del sector nororiental de la Avenida Costanera.

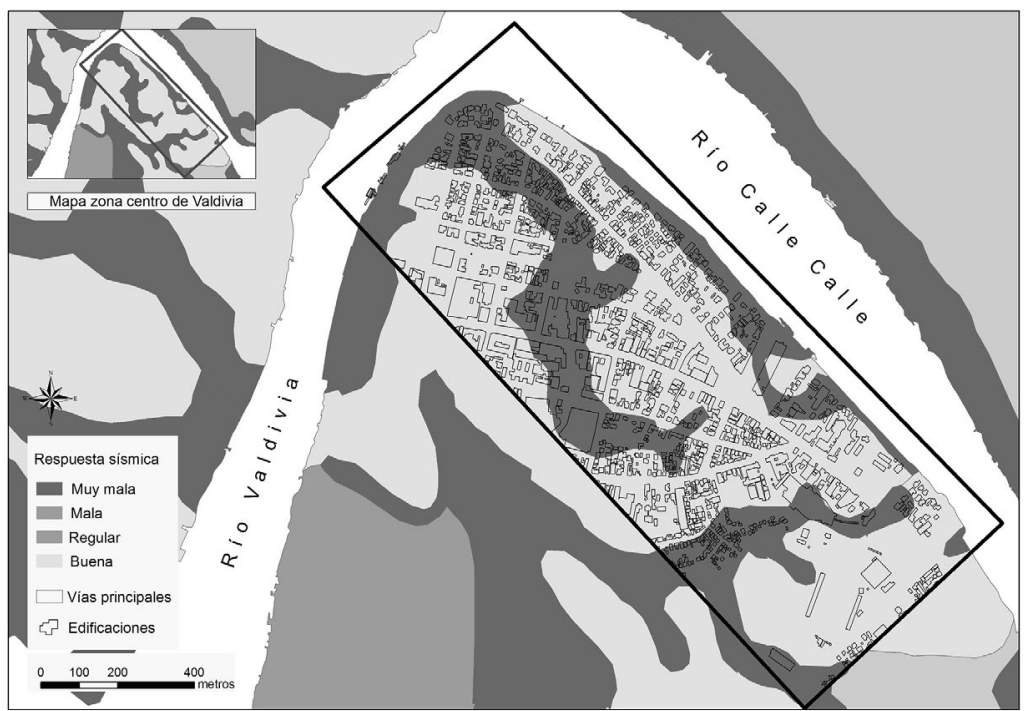

Fuente: Arenas, et al., (2004). Elaboración propia. 
En sectores muy puntuales se pudo apreciar una caída de bloques de esquistos micáceos que constituyen el enrocado. Cabe consignar que en numerosos tramos de este paseo peatonal se habían advertido desde hace más de 20 años ciertos deterioros, como por ejemplo algunas fisuras longitudinales en la acera, paralelas a la ribera, y cierto desnivel en algunos paños del pavimento. Asimismo, y principalmente por acción antrópica, grandes bloques de esquistos apilados para construir el muro de contención habían sido desplazados e incluso retirados, debilitando su capacidad de soporte.

En el sector de Beneficencia se concentró la mayor parte de las viviendas que resultaron con daños graves, desplomándose algunas y hundiéndose otras hasta 50 centímetros. Según el Director de Obras Municipales y Jefe de Emergencias de la Municipalidad de Valdivia, en este sector las casas edificadas no cuentan con permisos municipales autorizados dado que el terreno no es apto para la construcción (Diario Austral, 2010). Varias calles resultaron con roturas en aceras y calzadas, y también daños en algunas matrices de agua (Figura 9). Fueron relativamente escasos los daños en otras áreas de Valdivia, como por ejemplo el caso del Hospital Regional, ubicado en un sector alejado del centro comercial de la ciudad, experimentó fisuras en uno de sus edificios.

Figura 9. Mapa de respuesta sísmica del sector beneficencia.

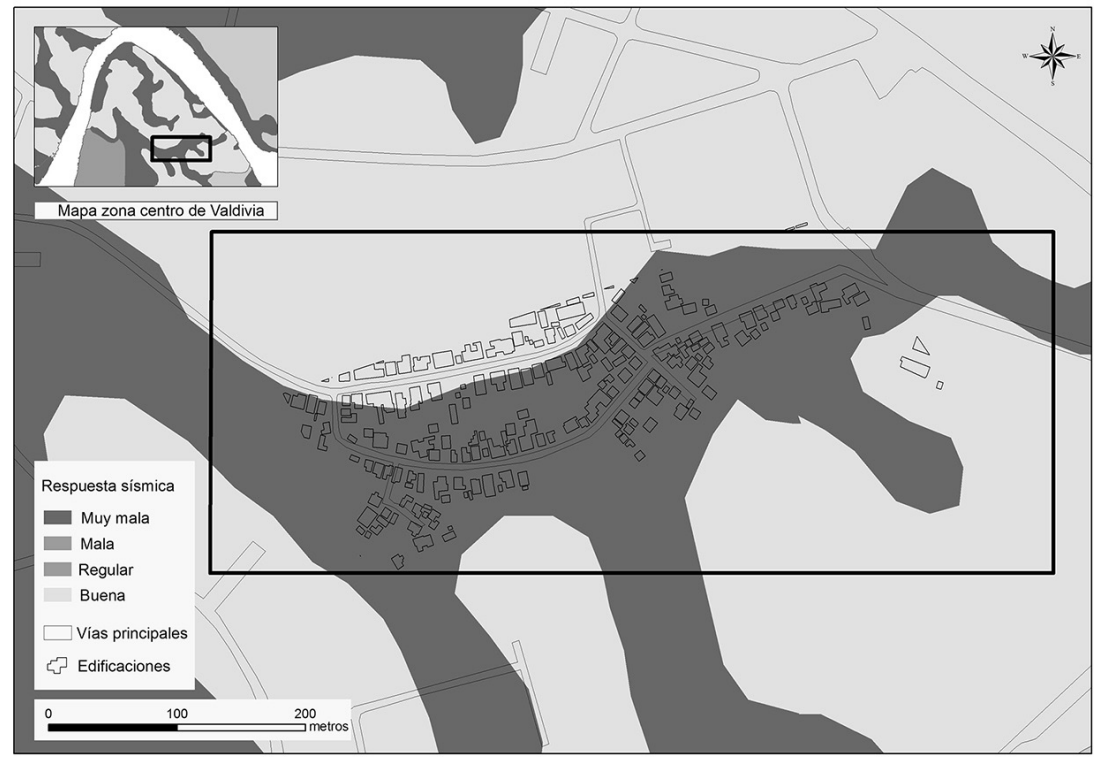

Fuente: Arenas, et al., (2004). Elaboración propia.

\section{CONCLUSIONES}

A la luz de los efectos del sismo del 27 de febrero de 2010 en Valdivia se puede concluir que con toda claridad se presentó visualmente la respuesta de los rellenos artificiales al paso del tiempo y a la solicitación sísmica. Por ejemplo, durante las cuatro décadas y media transcurridas desde la reconstrucción de la avenida Costanera el material de relleno que soportan tanto el muro de concreto como el enrocado experimentaron una compactación diferencial y un efecto de socavamiento subterráneo hacia el río que dejó en ciertas partes las losas de concreto colgadas por la formación de cámaras subterráneas. Durante el sismo de febrero 2010, al paso de las ondas sísmicas, el terreno experimentó una amplificación del movimiento a causa del tipo de material, lo que unido a lo anterior permitió el colapso del pavimento cuando el suelo dejó de tener la resistencia para sostener las losas encima.

Las estructuras dañadas por el sismo mostraron una marcada concentración en su distribución espacial sobre la superficie urbana de la ciudad de Valdivia. Con base en la información oficial, la intensidad con la que se percibió el sismo en Valdivia alcanzó un valor sólo moderado en la escala de Mercalli (Servicio Sismológico, 2010). No obstante, de acuerdo con los antecedentes de sismos anteriores (Rojas, 2000, 2010), es habitual que se manifiesten diferencias en la percepción y en los efectos en diversos sectores de la 
ciudad. Subiabre et al., (1986) concluyeron que, de acuerdo a los antecedentes de los suelos de fundación, en aquellos sectores que experimentaron los mayores daños para el sismo de 1960 las características de los materiales geológicos estratificados generaron muy importantes efectos de amplificación dinámica de los suelos. Esta conclusión está refrendada por el mapa de respuesta sísmica para la ciudad de Valdivia, elaborado por el Servicio Nacional de Geología y Minería (SERNAGEOMIN) (Arenas, Behlau y Hanisch, 2004), el cual zonifica la ciudad con base en la amplificación sísmica que experimentan los diferentes tipos de suelos. En concreto, esta amplificación se expresa en unidades en la escala Modificada de Mercalli en que se incrementa la intensidad sísmica local producto de las características geotécnicas básicas del suelo de fundación que hay en cada lugar.

Numerosos sectores de la ciudad poseen suelos de tales características que durante los sismos se generan allí incrementos de la intensidad en al menos 2,5 grados e incluso superiores a 3 grados Mercalli. En 1960, con ocasión del gran terremoto del sur de Chile, esos terrenos experimentaron intensidades de al menos VII e incluso mayores a IX en la escala de Mercalli (Arenas, Belhau y Hanisch, 2004). Estas zonas de altos incrementos de intensidad sísmica se localizan parcialmente sobre la llanura de inundación fluvial (Rojas, 2003), terrenos con cotas muy bajas (menores a 5 metros e incluso por debajo de 3 metros sobre el nivel del río) que en las márgenes del río Calle Calle - Valdivia constituyen la superficie donde se desarrollan los llamados "Barrios Bajos" de la ciudad, pero también ciertos sectores de los barrios Collico, Las Ánimas, Miraflores y Alto Guacamayo (Rojas, 2000, 2003, 2010) y por cierto el sector de Beneficencia. Los humedales riparianos y los interiores, junto con las vegas y sobre todo las áreas constituidas por rellenos artificiales, presentan una muy alta amplificación sísmica potencial, la que puede superar los 3 grados Mercalli. Durante el sismo de mayo de 1960 las intensidades sísmicas superaron en esos sectores el valor IX en la Escala Modificada de Mercalli, generándose en ellos la mayor destrucción a la infraestructura urbana.

A la luz de estos antecedentes, se puede concluir que también durante el sismo del 27 de febrero de 2010 pudo apreciarse en Valdivia una distribución de los efectos condicionada por la distribución espacial de los tipos de suelos de fundación. Consecuentemente con lo anterior, localmente la intensidad Mercalli debe haberse incrementado en al menos 2 grados en los sectores de relleno artificial ubicados en las riberas fluviales, en el barrio Beneficencia y en la zona del antiguo pantano que cruzaba el casco histórico de la ciudad en sentido SE-NW. Problemas potenciales asociados a estos suelos de mala calidad son la subsidencia por sobrecarga; también es común en ellos la licuefacción de sedimentos debido al exceso de presión de agua, y el desplazamiento lateral (González de Vallejo et al., 2004). Debido a la falta de confinamiento y al alto grado de saturación, Arenas, Behlau y Hanisch (2004) señalan que en las riberas fluviales se pueden producir deslizamientos de estos materiales, lo cual se condice plenamente con lo observado durante el sismo del año 2010 en la costanera de Valdivia.

De acuerdo con los antecedentes de la sismicidad histórica y con lo acontecido en la ciudad el 27 de febrero de 2010, la respuesta sísmica marcadamente diferencial de los diferentes barrios de Valdivia demuestra la importancia de los estudios geomorfológicos detallados para contribuir a reconocer y delimitar las áreas más vulnerables ante los eventos sísmicos extremos. Por ejemplo, los paleocauces y los humedales de diverso tipo pueden constituirse en unidades geomorfológicas potencialmente vulnerables a la amenaza sísmica en razón de las características físico-mecánicas de los suelos propios de esas geoformas, o de aquellas de los suelos de fundación resultantes del relleno artificial. Además, pueden ser vulnerables a fenómenos hidrometeorológicos (anegamientos, inundaciones) en función de variables como por ejemplo la cota del terreno, ya sea la natural o aquella alcanzada según la magnitud del relleno artificial, la cercanía a las riberas fluviales, los obstáculos artificiales al drenaje y el grado de impermeabilización de la superficie por los diferentes usos del suelo en la ciudad.

A la luz de esta realidad, los efectos del sismo del 27 de febrero de 2010, así como los del gran terremoto de mayo de 1960 en Valdivia, constituyen excelentes ejemplos para destacar la importancia de las propiedades de los suelos en el comportamiento de las estructuras para resistir la solicitación sísmica. Indiscutiblemente, muchos daños se originaron por falla del terreno, pero en muchos casos también se trató de errores en el diseño y/o en la calidad de la construcción. Al analizar la actual ocupación del suelo en Valdivia resalta el hecho que en zonas que experimentaron la mayor destrucción para el sismo 
de 1960 y en algunas de las actuales áreas de expansión de la ciudad con tipos de suelo similares a los de las anteriores, se ha levantado un gran número de infraestructura residencial, industrial, comercial y de servicios.

Actualmente puede apreciarse en la ciudad de Valdivia una diversidad de situaciones de ocupación de los antiguos lechos de los ríos (paleocauces) y depresiones que formaban pantanos, lagunas y vegas, ahora parcialmente rellenados e incluso directamente ocupados por edificaciones que han asentado sus cimientos en estos espacios deprimidos, receptores de aguas lluvias y de aguas subsuperficiales.

Por todo lo anterior resulta fundamental que en la planificación de su uso potencial se tenga en consideración la alta vulnerabilidad de ese tipo de terrenos frente a las amenazas naturales, en especial las de tipo sísmico e hidrometeorológico. Esto implica, además, un adecuado diseño arquitectónico e ingenieril de la infraestructura que allí se levante y un irrestricto respeto a éste en todas las etapas de la construcción.

Al respecto, para su utilización como suelos de fundación, Arenas et al., (2004) recomiendan que en aquellos de relleno artificial con muy mala aptitud para la construcción, los edificios sean de máximo dos pisos con fundación somera (losa rígida de hormigón). En aquellos suelos de aptitud mala a regular y para edificios ligeros, la fundación puede ser somera con losa de hormigón rígida, mientras que para los edificios pesados se requiere imprescindiblemente de una fundación profunda (pilotes) hasta encontrar capas potentes de arenas. En caso de tener que rellenar grandes superficies, según estos mismos autores se deben elaborar terraplenes construidos en varias capas de máximo 1 metro de espesor aplicando algún método de sobrecarga temporal para aumentar la compactación. En el caso de rellenar áreas reducidas, debiera realizarse una excavación y un reemplazo de los suelos compresibles por grava. La colocación de una lámina de geotextiles con una capa de ripio es importante para permitir el drenaje lateral y la excavación de pozos rellenos con grava cada 20 metros para el drenaje vertical.

\section{BIBLIOGRAFÍA}

ALMONACID, F. (1998): Valdivia, 1870-1935, imágenes e historias. Ed. Facultad de Filosofía y Humanidades, Universidad Austral de Chile. $2^{a}$ edición. Valdivia, 111 p.

ARENAS, M., BEHLAU, J. y HANISCH, J. (2004): "Características geotécnicas básicas y respuesta sísmica". En: Geología para planificación territorial del área de Valdivia. Servicio Nacional de Geología y Minería, Carta Geológica de Chile, Serie Geología Ambiental, 6 mapas escala 1:100.000 y un mapa escala 1:25.000. Santiago.

BARRIENTOS, S. (2010): "Terremoto ( $M=8.8)$ del 27 de febrero de 2010 en Chile", en Rev. Asoc. Geol. Argent., vol.67 (3), pp. 412-420.

BAROZZI, R. y LEMKE, R. (1966): "El suelo de fundación de la ciudad de Valdivia”. En: Estudios Geotécnicos $\mathrm{N}^{\circ}$ 1. Instituto de Investigaciones Geológicas. Santiago. Chile. 1 mapa. 1 p.

DIARIO EL AUSTRAL:

- (2010 a): "Municipio realizó balance de daños en la capital regional a días de la tragedia" en Diario El Austral, región de Los Ríos. Edición 5 de marzo de 2010. http://www.australvaldivia.cl/prontus4 nots/site/artic/20100305/pags/20100305153130.html. Con acceso el 12 de abril de 2013.

- (2010 b): "Daños por más de 80 millones de pesos dejó el terremoto en Valdivia" en Diario El Austral, región de Los Ríos. Edición del 22 de marzo de 2010. http://www.australvaldivia.cl/prontus4 nots/ site/artic/20100322/pags/20100322000609.html. Con acceso el 12 de abril de 2013.

DOP, (2011): "Ministra Von Baer encabezó inauguración de nuevo tramo de la Costanera" en Noticias Dirección de Obras Portuarias (DOP). 23 de febrero 2011. http://www.dop.cl/noticias/Paginas/ DetalledeNoticias.aspx?item=96. Con acceso el 12 de abril de 2013.

DUKE, C. M y LEEDS, D.J. (1963): "Response of soils, foundations, and earth structures to the chilean earthquakes of 1960", en Bulletin of the Seismological Society of America, 53 (2), pp. 309-357. 
DOYEL, W., MORAGA, A. y FALCÓN, E. (1963): "Relation between the geology of Valdivia, Chile and the damage produced by the earthquake of 22 May 1960", en Bulletin of the Seismological Society of America, 53 (6), pp. 1313-1345.

GONZÁlez DE VALlEJO, L.; FERRER, M.; ORTUÑO, L. y OTEO, C. (2004): Ingeniería Geológica. Pearson/Prentice Hall, Madrid. 715 p.

GOLL, F. (1904): "Die Erdbeben Chiles. Die Erdbeben und Vulkanausbrüche in Chile bis zum Ende des Jahres 1879 nebst einigen allgemeinen Bemerkungen zu diesen Erdbeben", en Münchener Geographische Studien, No 14, 137 p.

GORE (2012): "Realizan balance de los efectos del sismo en la región de Los Ríos". http://www. goredelosrios.cl/noticias/realizan-balance-de-los-efectos-del-sismo-en-la-region-de-los-rios.html. Con acceso el 12 de abril de 2013.

GREVE, F. (1964): Historia de la sismología en Chile. Universidad de Chile. Instituto de Geofísica y Sismología. Publicación No 40. Santiago. 94 p.

GUARDA, G. (2001): Nueva Historia de Valdivia. Ediciones Universidad Católica de Chile, Santiago. 862 p.

HANKS T. C. \& KANAMORI, H. (1979): "A moment magnitude scale". Journal of Geophysical Research 84 (B5), pp. 2348-2350.

LOMNITZ, C.:

- (1970): "Major earthquakes and tsunamis in Chile during the period 1535 to 1955", en Geologische Rundschau, Vol. 70, N 59, pp. 938-960.

- (2004): "Major earthquakes of Chile: A historical survey 1535-1960", en: Seismological Research Letters, 75 (3), pp. 68-378.

ROJAS, C.:

- (2000): "Los Riesgos Naturales en la ciudad de Valdivia, Chile. Importancia de los factores físicos en la evaluación de la Vulnerabilidad". En Seminario Taller Internacional La ciudad Intermedia sustentable. 20-22 septiembre 2000. Universidad Nacional de Piura. Piura, Perú, 23 p.

- (2002): "Zonificación y evaluación de áreas de amenaza de inundación en la ciudad de Valdivia". Tesis para optar al grado de Magister en Ciencias mención en Recursos Hídricos. Escuela de Graduados. Facultad de Ciencias, Universidad Austral de Chile. 246 p.

- (2003): "Geomorfología del sitio de la ciudad de Valdivia", en XXIV Congreso Nacional y IX Internacional de Geografía. 10-14 de noviembre de 2003. Universidad Católica de Valparaíso, Valparaíso.

- (2005a): "El rol de los paleocauces y humedales en la evaluación de las amenazas naturales en la ciudad de Valdivia", en: Revista Geográfica de Valparaíso, № 35, pp. 243 - 251.

- (2005b): "Geomorfología aplicada a amenazas naturales en la ciudad de Valdivia, Chile". En: María Celia García (compiladora). Ciudades Intermedias. Problemas de su estructura y funciones. Conflictos ambientales y sociales en los años 2000. Centro de Investigaciones Geográficas UNICEN. Tandil Argentina.

- (2010): Valdivia 1960. Entre aguas y escombros. Ediciones Universidad Austral de Chile. Valdivia. $165 \mathrm{p}$.

ROJAS, C. y MARDONES, M. (2003): "Las inundaciones en la ciudad de Valdivia: eventos históricos 1899 - 2002", en Revista Geográfica de Valparaíso, № 34, pp. 227 - 242.

RUBILAR, H., JESSEL, B., ROJAS, C. y RAMÍREZ, C. (2007): "Reconstruction of paleoenvironment to understand involved processes on landscape development; an important tool for long term research and management at the Valdivian urban wetlands (Chile)". International Association for Landscape Ecology (IALE) World Congress, 8 - 12 July 2007. Wageningen, The Netherlands. Book of Abstracts Part I, p. 531.2007 
SAINT-AMAND, P. (1961): Los Terremotos de Mayo, Chile 1960. An eyewitness account of the greatest natural catastrophe in recent history. Michelson Laboratories Technical Article 14 U.S. Naval Ordnance Test Station, China Lake, California. 39 p.

SERNAGEOMIN (2010): Efectos geológicos del sismo del 27 de Febrero 2010: evaluación preliminar y Propuesta de actividades futuras. (INF-NAC-01). 16 p. Servicio Nacional de Geología y Minería (SERNAGEOMIN). http://www.sismo24.cl/500sismos/00imgsismos/600pdf/300infoSernag 2010.pdf. Con acceso el 18 de abril de 2013.

SUBIABRE, A., VARELA, C., ROJAS, C. y KUNZE, T. (1986): "Sectores de riesgo por movimientos sísmicos en la ciudad de Valdivia”. Resúmenes de Ponencias. VIII Congreso Nacional de Geografía. Valdivia. pp. $205-211$.

TAULIS, E. (1938): "Terremotos y grandes temblores habidos en Chile" en Revista Chilena de Historia Natural, pp. 302 - 312.

URRUTIA, R. y LANZA, C. (1993): Catástrofes en Chile, 1541-1992. Editorial La Noria, Santiago. 440 p.

WATANABE, T. y KARZULOVIC, J. (1960): "Los movimientos sísmicos del mes de mayo de 1960 en Chile", en Anales de la Facultad de Ciencias Físicas y Matemáticas. Universidad de Chile, $\mathrm{N}^{\circ} 17$, pp. $23-64$.

WEISCHET, W. (1960): Contribución al estudio de las transformaciones geográficas de la parte septentrional del sur de Chile por efecto del sismo del 22 de mayo de 1960", en Anales de la Facultad de Ciencias Físicas y Matemáticas, Universidad de Chile, № 17, pp. 95 - 128. 